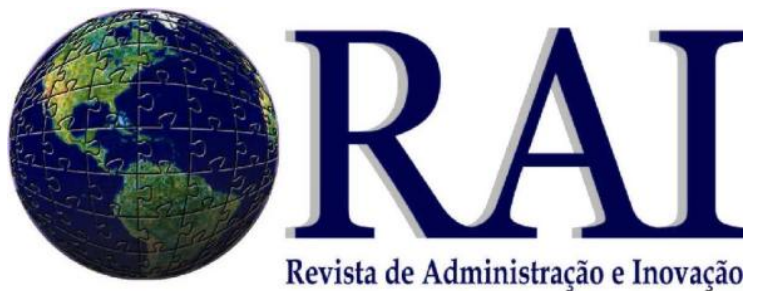

ARTIGOS

\title{
ESTRATÉGIAS DE INOVAÇÃO DAS EMPRESAS METALÚRGICAS NO SETOR SUCROALCOOLEIRO DE PIRACICABA
}

\section{Zeferino Saraiva Henriques}

Mestre profissionalizante em Mestrado Profissional em Administração pela

Universidade Metodista de Piracicaba - UNIMEP

Professor assistente da Universidade Pedagógica Moçambique - UPM

E-mail: zeferinohenriques@yahoo.com.br [Brasil]

\section{Mário Sacomano Neto}

Pós-Doutor pela Universidade Metodista de Piracicaba - UNIMEP

Professor titular da Universidade Metodista de Piracicaba - UNIMEP

E-mail: msacomano@unimep.br [Brasil]

\section{Sílvia Helena Ramos Valladão de Camargo}

Doutora em Administração pela Universidade de São Paulo - USP

Professora titular da Universidade Metodista de Piracicaba - UNIMEP

E-mail: shcamargo.ml@ convex.com.br [Brasil]

\section{Antônio Carlos Giuliani}

Doutor em Educação pela Universidade Metodista de Piracicaba - UNIMEP

Professor titular da Universidade Metodista de Piracicaba - UNIMEP

E-mail: cgiuliani@unimep.br [Brasil]

\section{Osvaldo Elias Farah}

Doutor em Administração pela Universidade de São Paulo - USP

Professor titular do Programa de Pós-Graduação Stricto Sensu em Administração da

Universidade Nove de julho - UNINOVE

E-mail: oefarah@uninove.br [Brasil]

\section{Resumo}

A inovação é o motor do desenvolvimento econômico e estudar os processos pelos quais inovações são introduzidas e difundidas é um dos maiores desafios que se coloca perante a economia regional e global. Este artigo analisa as estratégias de inovação de empresas metalúrgicas fornecedoras do setor sucroalcooleiro e algumas pertencentes ao arranjo produtivo local do álcool de Piracicaba (APLA). A pesquisa é exploratória e descritiva e foi realizada com 25 empresas do setor metal-mecânico, em grande parte micro, pequenas e médias empresas. Os resultados da pesquisa revelam que as inovações das micro e pequenas metalúrgicas ocorrem mais em produtos do que em processos produtivos. Dentre as dificuldades encontradas pelas empresas, apresenta-se a carga tributária e a elevada taxa de juros, assim como acesso restrito a tecnologias, crédito e mercados. Resultados da pesquisa também revelam que a inserção das empresas no APLA tem gerado maiores possibilidades de inovação em produtos e processos para suportar o crescimento e avanço do etanol brasileiro nos mercados mundiais.

Palavras- chave: Arranjos produtivos locais, inovação, pequenas empresas

RAI - Revista de Administração e Inovação ISSN: 1809-2039

Organização: Comitê Científico Interinstitucional

Editor Científico: Milton de Abreu Campanario

Avaliação: Double Blind Review pelo SEER/OJS

Revisão: gramatical, normativa e de formatação

RAI - Revista de Administração e Inovação, São Paulo, v. 5, n. 2, p. 92-111, 2008. 
ARTIGOS - Estratégias de inovação das empresas metalúrgicas no setor

Sucroalcooleiro de Piracicaba

\section{INTRODUÇÃO}

O cenário empresarial, repleto de mudança e complexidade crescente, com empresas atuando de forma isolada e atomística, não é mais adequado para suportar níveis elevados de competição. Para sustentar sua vantagem competitiva, um número crescente de empresas está estabelecendo múltiplas alianças de diferentes tipos, constituindo parcerias, joint ventures, redes, inclusive virtuais. A busca da competitividade das empresas se reforça sob essa perspectiva, onde é absolutamente decisivo o papel e a importância das relações e redes interfirmas que atravessam fronteiras das indústrias e países (TAUHATA; MACEDO-SOARES, 2004).

São visíveis as mudanças que estão ocorrendo mundialmente, não só na tecnologia, como em avanços significativos nas ciências computacionais, eletrônica, robótica, que vêm alterando profundamente os processos produtivos, como também a dinâmica dos mercados e a forma de vida da sociedade (HITT; IRELAND; HOSKISSON, 2002, p. 12).

No conjunto das transformações que marcaram a passagem do milênio, renasceu o interesse sobre o papel que as micro e pequenas empresas podem ter na reestruturação produtiva, assim como no desenvolvimento de regiões e países. Esse interesse coincidiu com: (1) o reconhecimento de que o aproveitamento das sinergias coletivas, geradas pela participação em aglomerações produtivas locais, efetivamente fortalece as chances de sobrevivência e crescimento dessas empresas, constituindo-se importante fonte geradora de vantagens competitivas duradouras; (2) os processos de aprendizagem coletiva, cooperação e dinâmica inovativa desses conjuntos de empresas assumem importância ainda mais fundamental para o enfrentamento dos novos desafios colocados pela difusão da chamada Sociedade da Informação ou Era de Conhecimento, crescentemente globalizada; e (3) o entendimento desse conjunto de questões passou a constituir-se uma das principais preocupações e alvos das novas políticas de promoção de desenvolvimento tecnológico e industrial, com ênfase nas formas e instrumentos de promoção das micro e pequenas empresas (LASTRES; CASSIOLATO, 2003, p. 21).

A estratégia baseada nos arranjos e sistemas produtivos locais tem ganhado revelada preferência pelas políticas públicas de geração de emprego e renda e de desenvolvimento regional e local, com maior ênfase nos países desenvolvidos e menor avanço nos países em desenvolvimento. Ao mesmo tempo, essa estratégia tem servido de mecanismo estruturador e organizador das micro, pequenas e médias empresas, tendo ocupado rapidamente o lugar dos mecanismos institucionais que apoiavam individualmente ou isoladamente essas empresas. Também nesse caso, o processo de adoção de novos mecanismos tem caminhado com maior rapidez nos países desenvolvidos, e com mais lentidão nos países em desenvolvimento. (AMARAL FILHO et al., 2003, p. 85).

De acordo com a definição proposta pela Rede de Pesquisas em Sistemas Produtivos e Inovativos Locais (2003 apud LASTRES; CASSIOLATO, 2003), arranjos produtivos locais são aglomerações territoriais de agentes econômicos, políticos e sociais - com foco em um conjunto específico de atividades econômicas - que apresentam vínculos, mesmo que incipientes. Geralmente há a participação e a interação de empresas - que podem ser desde produtoras de bens e serviços finais, até fornecedores de insumos e equipamentos, prestadoras de serviços, comerciantes, clientes, dentre outras - e suas variadas formas de representação e inovação. Os aglomerados podem ser caracterizados como uma nova forma de organização produtiva, principalmente no que diz respeito às pequenas e médias empresas (PORTER, 1989).

RAI - Revista de Administração e Inovação, São Paulo, v. 5, n. 2, p. 92-111, 2008. 
A prevalência dos aglomerados nas economias, em vez de empresas e setores isolados, proporciona importantes discernimentos sobre a natureza da competição e o papel da localização na vantagem competitiva.

Buscando entender a relação entre a formação do APLA e o desenvolvimento das pequenas empresas metalúrgicas, este estudo tem como objetivo analisar as estratégias de inovação utilizadas pelas micro e pequenas empresas metalúrgicas que atuam no setor agroindústria sucroalcooleiro.

A pesquisa também permitiu verificar se há relações de cooperação entre empresas e seus fornecedores e identificar as ações estratégicas implantadas na formação do APLA, como uma tentativa de incentivar as empresas ao crescimento e, consequentemente, desenvolvimento do aglomerado.

No sentido de orientar a pesquisa foram qualificadas algumas proposições:

Proposição 1. As inovações nas micro e pequenas metalúrgicas ocorrem mais em processos produtivos do que em produtos.

Proposição 2. As estratégias das empresas estão mais voltadas em atender as encomendas da empresa ancora do que buscar novos mercados.

Proposição 3. As instituições acadêmicas não estão criando ações para o fomento de inovações nas micro e pequenas metalúrgicas do APLA.

Proposição 4. O esforço do principal ator (governança) em aproximar as empresas do segmento metalúrgico não tem surtido os efeitos desejados para aumento da inovação das micro e pequenas metalúrgicas.

A revisão da literatura e a metodologia da pesquisa são apresentadas nos tópicos a seguir.

\section{INOVAÇÃO}

Há várias denominações para a inovação. Para Sáenz e Sousa Paula (2006, p. 46), a inovação é um processo sistêmico, interativo, multidisciplinar e de múltiplos e diferentes atores. Toda inovação é um processo de aprendizagem, no qual novos conhecimentos são gerados, outros são transferidos e outros já existem nas instituições participantes. Esse conjunto de novos e existentes conhecimentos é assimilado e interconectado para introduzir na sociedade uma nova tecnologia.

Para Organização para Cooperação Econômica e Desenvolvimento (2004, p. 37), a arena externa na qual as empresas podem manobrar compreende instituições e condições que, em sua maioria, foram estabelecidas por razões não ligadas à inovação. $\mathrm{O}$ ambiente institucional geral fornece as condições estruturais nas quais a inovação pode ocorrer. Entre os elementos que o compõem estão: sistema educacional básico; intraestrutura de comunicações; instituições financeiras; contexto legal e macroeconômico; acessibilidade ao mercado; estrutura da indústria e ambiente competitivo.

De acordo com Hamel (2006), não é possível fazer sempre a mesma coisa. A ausência de inovação pode ser decorrente de dois fatores: o fato de os funcionários menos graduados na hierarquia das empresas não serem treinados para o pensamento

RAI - Revista de Administração e Inovação, São Paulo, v. 5, n. 2, p. 92-111, 2008. 
ARTIGOS - Estratégias de inovação das empresas metalúrgicas no setor

Sucroalcooleiro de Piracicaba

inovador e a ausência de processos ou de mecanismos de apoio para estimular a inovação.

A inovação em gestão é a inovação dos princípios e processos gerenciais que, de fato, transformam as práticas das tarefas dos executivos e as maneiras como são realizadas. De acordo com Hamel (2006), considerando-se uma empresa como um conjunto de processos que transformam inputs em outputs, como, por exemplo, a transformação do trabalho e do capital em produtos e serviços, pode-se caracterizar a inovação em três tipos:

\section{- $\quad$ inovação em gestão; \\ - $\quad$ inovação tecnológica ou de produto; \\ - inovação operacional.}

Uma inovação tecnológica de produto é a implantação/comercialização de um produto com características de desempenho aprimoradas, de modo a fornecer objetivamente ao consumidor serviços novos ou aprimorados. Uma inovação de processo tecnológico é a implantação/adoção de métodos de produção ou comercialização novos ou significativamente aprimorados. Pode envolver mudanças de equipamentos, recursos humanos, métodos de trabalho ou uma combinação destes (ORGANIZAÇÃO PARA COOPERAÇÃO ECONÔMICA E DESENVOLVIMENTO, 2004).

Para Cipolla, Cavalcanti e Souza (2007, p. 248) as atividades inovativas são classificadas em sete grupos, a saber:

- $\quad$ pesquisa e desenvolvimento: trabalho criativo desenvolvido de maneira sistemática, com o objetivo de aumentar o conhecimento existente;

- $\quad$ engenharia industrial: aquisição ou mudanças nos meios de produção visando à manufatura do novo produto ou à aplicação do novo processo;

- $\quad$ início da produção: modificações de produtos e processos, treinamento de pessoal nas novas técnicas e lote experimental;

- $\quad$ marketing de novos produtos: atividades relacionadas ao lançamento do novo produto;

- $\quad$ aquisição de tecnologia intangível;

- $\quad$ aquisição de tecnologia tangível;

- design.

Há um consenso entre os autores com relação ao amplo conjunto de possibilidade de inovação nas empresas, desde o operacional, gerencial até o nível estratégico de mercado.

O desenvolvimento das novas tecnologias e a globalização dos mercados poderiam ser uma explicação da primazia que se tem dado à inovação de produto e de processo nas últimas décadas, porém não justifica negar o papel estratégico da inovação relacionada à organizacional (BEJERANO, 2006, p. 82).

É possível distinguir, segundo Cipolla, Cavalcanti e Souza (2007), a inovação em incremental ou radical. A incremental é o resultado dos aprimoramentos técnicos de base contínua; já a inovação radical produz grande impacto econômico ou mercadológico e está relacionada ao desenvolvimento de um novo produto, processo ou forma inteiramente novos de organização de produção.

A capacidade tecnológica depende também das características da estrutura da empresa, de sua força de trabalho e das facilidades de que dispõe, de sua estrutura

RAI - Revista de Administração e Inovação, São Paulo, v. 5, n. 2, p. 92-111, 2008. 
financeira, de sua estratégia, dos mercados, dos concorrentes, das alianças com outras empresas ou com universidades e, acima de tudo, de sua organização interna. Muitos desses aspectos são complementares. Uma determinada estrutura de competência caminhará de mãos dadas com um tipo particular de estratégias, de estrutura financeira e assim por diante (ORGANIZAÇÃO PARA COOPERAÇÃO ECONÔMICA E DESENVOLVIMENTO, 2004, p. 41).

A capacidade tecnológica de uma empresa está, em parte, inserida em sua força de trabalho. Empregados capacitados são considerados recurso-chave de uma empresa inovadora. Sem trabalhadores capacitados, a empresa não conseguirá dominar novas tecnologias e, muito menos, inovar. Além de pesquisadores, as empresas necessitam de engenheiros que possam gerenciar as inovações de fabricação, de vendedores capazes de entender a tecnologia que estão vendendo (tanto para vendê-la, como para trazer de volta as sugestões dos clientes) e gerentes gerais familiarizados com as questões tecnológicas.

Nessa pesquisa, o foco da inovação relaciona-se com as inovações em processos (modificações de produtos e processos, treinamento de pessoal nas novas técnicas) e produtos (atividades relacionadas ao lançamento do novo produto) nas micro e pequenas empresas metalúrgicas.

\subsection{INOVAÇÃO TECNOLÓGICA NAS MICRO E PEQUENAS EMPRESAS}

Diversos fatores contribuem para que as micro e pequenas empresas que atuam no setor sucroalcooleiro sejam mais competitivas; um deles é a inovação, ao permitir a melhoria nos processos, o aumento de produtividade e a agregação de valor aos produtos, criando, assim, um diferencial nesse mercado.

Um critério generalizado em vários países do terceiro mundo baseia-se na idéia de que o fortalecimento da infraestrutura e o desenvolvimento de setores estratégicos conduziriam ao desenvolvimento do país. Inclusive, vários planos de desenvolvimento têm sido propostos e aplicados seguindo essa proposta (SÁENZ; SOUSA PAULA, 2006, p. 43).

A inovação é fundamental para o processo produtivo e nem sempre requer alta tecnologia. Pode envolver inovação de processos, descoberta de novos nichos de mercado ou novas aplicações para um produto.

A capacidade de determinar a escala das atividades inovadoras, as características das empresas inovadoras e os fatores internos e sistêmicos que podem influenciar a inovação são um pré-requisito para o desenvolvimento e a análise de políticas que visem incentivar a inovação tecnológica (ORGANIZAÇÃO PARA COOPERAÇÃO ECONÔMICA E DESENVOLVIMENTO, 2004, p. 5).

O conceito de inovação, bem como sua prática, não é novo. Desde que a teoria das organizações foi sendo elaborada, e os conceitos da administração desenvolvidos, a inovação sempre esteve presente. A inovação pode ser relacionada com a criação de um novo produto, um serviço diferente que passa a ser oferecido a um determinado mercado e, mesmo com os processos, da forma com que a organização é estruturada (DORNELAS, 2003).

Inovação tem a ver com a mudança, fazer coisas de forma diferente, de criar algo novo, de transformar o ambiente onde está inserido. É algo mais abrangente que apenas a comum relação que se faz com a

RAI - Revista de Administração e Inovação, São Paulo, v. 5, n. 2, p. 92-111, 2008. 
ARTIGOS - Estratégias de inovação das empresas metalúrgicas no setor

Sucroalcooleiro de Piracicaba

criação de novos produtos ou serviços. É um termo econômico ou social, mais do que técnico (DORNELAS, 2003, p. 17).

A inovação é o instrumento específico dos empreendedores, o meio pelo qual exploram a mudança como uma oportunidade para um negócio diferente. Os empreendedores precisam buscar, de forma deliberada, as fontes de inovação, as mudanças e seus sintomas que indicam oportunidades para que a inovação tenha êxito (DORNELAS, op. cit.).

O investimento em novas tecnologias, num quadro de expansão e diversificação da produção, seja para o mercado interno, como para o externo, é fundamental para que o país consiga gerar mais empregos, prestar serviços de maior qualidade e ocupar um papel mais estratégico na hierarquia econômica internacional. Ao contribuir para a expansão da demanda e da produtividade e, ao ocupar espaços mais nobres nas cadeias produtivas mundiais, o investimento em tecnologia foi um dos geradores de empregos. Além disso, a recuperação da economia com políticas de redução de desigualdade permitiu que a população de baixa renda tivesse acesso ao mercado (cerca de 80 milhões de pessoas, segundo o critério de pobreza relativa).

Assim, percebe-se que o crescimento da economia brasileira, durante o período de industrialização, não esteve apoiado apenas na ampliação da capacidade produtiva, mas também na inovação tecnológica, que permitiu o aumento dos níveis de produtividade.

Portanto, para que as empresas brasileiras sejam micro, pequenas, médias ou grandes, possam garantir uma política mais adequada para investirem no mercado nacional e internacional, deverão qualificar e inovar tecnologicamente. A inovação é o motor do desenvolvimento econômico e estudar os processos pelos quais novas inovações são introduzidas e difundidas espacialmente é um dos maiores desafios que se coloca perante a economia regional.

\section{AGLOMERADOS DE EMPRESAS E ARRANJOS PRODUTIVOS LOCAIS}

Aglomerados e arranjos produtivos locais são entendidos como sinônimos nesta pesquisa. A expressão arranjo produtivo local (APL) foi denominada a partir de uma reunião interministerial ocorrida no ano de 2002, na qual surgiu juntamente com políticas públicas específicas a esse tipo de arranjo.

Para Porter (1999, p. 211) "um aglomerado é um agrupamento geograficamente concentrado em empresas inter-relacionadas e instituições correlatas numa determinada área, vinculadas por elementos comuns e complementares". O escopo geográfico varia de uma única cidade ou estado para todo o país ou mesmo uma rede de países vizinhos. Os aglomerados assumem diversas formas, dependendo de sua profundidade e sofisticação, mas a maioria inclui empresas de produtos ou serviços finais, fornecedores de insumos especializados, componentes, equipamentos e serviços, instituições financeiras e empresas em setores correlatos. Os aglomerados geralmente também incluem empresas em setores a jusante (ou seja, distribuidores ou clientes), fabricantes de produtos complementares, fornecedores de infraestrutura especializada, instituições governamentais e outras, dedicadas ao treinamento especializado, educação, informação, pesquisa e suporte técnico (como universidades, centros de altos estudos e prestadores de serviços de treinamento vocacional), e agência de normalização.

RAI - Revista de Administração e Inovação, São Paulo, v. 5, n. 2, p. 92-111, 2008. 
O termo aglomeração - produtiva, científica, tecnológica e/ou inovativa - tem como aspecto central a proximidade territorial de agentes econômicos, políticos e sociais (empresas e outras instituições e organizações públicas e privadas) (ALBAGLI; BRITO, 2003).

A identificação das partes constituintes do aglomerado exige que se adote como ponto de partida uma grande empresa ou uma concentração de empresas semelhantes, para em seguida se analisar a montante e a jusante a cadeia vertical de empresas e instituições. O passo seguinte consiste na análise horizontal, para identificar setores que utilizam distribuidores comuns ou que fornecem produtos ou serviços complementares. Com base no uso de insumos ou tecnologias especializadas semelhantes ou através de outros elos com os fornecedores, identificam-se cadeias horizontais de setores. Após a identificação dos setores e empresas do aglomerado, o passo subsequente é o isolamento das instituições que oferecem qualificações especializadas, tecnologias, informações, capital ou infraestrutura e órgãos coletivos envolvendo os participantes do aglomerado. $\mathrm{O}$ passo final consiste em procurar as agências governamentais e outros órgãos reguladores que exerçam influências significativas sobre os participantes do aglomerado (PORTER, 1999, p. 212).

O desenho das fronteiras do aglomerado é, em geral, uma questão de grau e envolve um processo criativo, fundamentado na compreensão dos elos e das complementaridades entre os setores de maior importância para a competição (PORTER, 1999). As fronteiras de um aglomerado devem abranger todas as empresas, setores e instituições com fortes elos verticais, horizontais ou institucionais. Quando os elos forem fracos ou inexistentes, a entidade, sem dúvida, não é parte integrante do aglomerado.

Os aglomerados variam em tamanho, amplitude e estágio de desenvolvimento. Alguns consistem, sobretudo, em empresas de pequeno e médio porte. Outros envolvem empresas de grande e pequeno porte. Alguns giram em torno de pesquisas universitárias, enquanto outros não apresentam ligações importantes com as universidades. Essas diferenças na natureza de aglomerados refletem diferenças na estrutura dos setores constitutivos.

Muitas das vantagens dos aglomerados decorrem das economias externas às empresas ou dos efeitos colaterais de vários tipos entre empresas e setores. Assim, os aglomerados seriam definidos como um sistema de empresas e instituições interrelacionadas, cujo valor como um todo é maior do que a soma das partes (PORTER, 1999). Um aspecto destacado pelo autor é o fortalecimento da capacidade de inovação.

A formação dos aglomerados cria um novo ambiente na localidade, geram novos papéis para os governos, são forças motriz para o aumento das exportações e desempenham o papel de ímãs na atração de investimentos externos, possibilitam novas modalidades de diálogo entre empresas, órgãos governamentais e instituições (escolas, universidades, ONGs, sindicatos, instituições e empresas de utilidade públicas).

Os aglomerados também incluem empresas em setores a jusante (distribuidores ou clientes), fabricantes de produtos complementares, fornecedores de infraestrutura especializada, instituições governamentais e outras, dedicadas ao treinamento especializado, educação, informação, pesquisa e suporte técnico, e agência de normatização. Lembrando que os órgãos governamentais possuem significativa influência sobre os aglomerados, bem como associações comerciais, entidades associativas do setor privado que, além de apoiar, fazem parte do cenário.

RAI - Revista de Administração e Inovação, São Paulo, v. 5, n. 2, p. 92-111, 2008. 
ARTIGOS - Estratégias de inovação das empresas metalúrgicas no setor Sucroalcooleiro de Piracicaba

O Serviço de Apoio às Micro e Pequenas Empresas (2005) define arranjos produtivos locais como empresas fisicamente próximas e fortemente relacionadas aos agentes locais que apresentam a mesma dinâmica econômica. Essa dinâmica pode ser traduzida por uma série de fatores diversos, tais como atividades semelhantes, mão-de-obra específica, matérias-primas similares, condições climáticas ou de solo, fornecimento a um cliente próximo, processos históricos e culturais. A característica predominante para a formação de um cluster é a forte aglomeração/concentração em uma mesma região.

Arranjo produtivo local constitui a aglomeração de um número significativo de empresas que atuam em torno de uma atividade produtiva principal, bem como de empresas correlatas e complementares como fornecedoras de insumos e equipamentos, prestadoras de consultoria e serviços, comercializadoras, clientes, entre outros, em um mesmo espaço geográfico (um município, conjunto de municípios ou região), com entidade cultural local e vínculo, mesmo que incipiente, de articulação, interação, cooperação e aprendizagem entre si e com outros atores locais e instituiçõos públicas ou privadas de treinamento, promoção e consultoria, escolas técnicas e universidades, instituições de pesquisa, desenvolvimento e engenharia, entidades de classe e instituições de apoio empresarial e de financiamento (ALBAGLI; BRITO, 2003).

\section{ARRANJO PRODUTIVO LOCAL DO ÁLCOOL DE PIRACICABA} (APLA)

O município de Piracicaba é pólo da Região de Piracicaba, formado pelos municípios de Águas de São Pedro, Capivari, Charqueada, Elias Fausto, Mombuca, Rafard, Rio das Pedras, Saltinho, Santa Maria da Serra e São Pedro, e integra a região administrativa de Campinas, ocupando uma área de 1.368,4 quilômetros quadrados. $\mathrm{O}$ município conta com excelentes opções de acesso rodoviário às regiões interiores de São Paulo e atualmente busca o desenvolvimento de outros modais de acesso ao seu território, como o hidroviário, o dutoviário, o ferroviário, além de ampliação do aeroviário, reforçando as alternativas do acesso à capital paulista e aos portos de Santos e São Sebastião (SANTOS, 2007, p. 20).

O município de Piracicaba teve sua constituição e evolução estreitamente ligadas às atividades agrícolas e industriais. Em toda a história da região, a atividade agrícola foi marcada de forma fundamental pela cana-de-açúcar. Como primeira cultura introduzida em Piracicaba, a cana manteve a primazia até fins do século passado, ao lado de outras culturas que se desenvolvem, de forma secundária como, por exemplo, o algodão, os cereais, as frutas e a criação de gado. Mesmo com a penetração do café nas regiões do interior de São Paulo, a atividade canavieira da região de Piracicaba não chega jamais a ser deslocada.

Piracicaba, situada em uma das regiões mais industrializadas e produtivas do Estado de São Paulo, é um centro nacional da tecnologia da produção do setor sucroalcooleiro, com numerosas instituições de ensino, centros de pesquisa e tecnologia na produção de açúcar e etanol. Seu parque industrial diversificado é responsável pela produção de equipes de toda a cadeia produtiva de álcool e de açúcar, ademais da produção da cana-de-açúcar, matéria-prima básica na produção de álcool e seus derivados, um total de 1.4 milhões de toneladas de açúcar e 500 milhões de litros de álcool por ano.

RAI - Revista de Administração e Inovação, São Paulo, v. 5, n. 2, p. 92-111, 2008. 
Essa estrutura permitiu a instalação, no município, do Pólo Nacional de Biocombustível, transformando a cidade em referência mundial na produção de álcool e permitindo a implantação de um aglomerado local de álcool.

No que se refere à indústria, Piracicaba, até a metade do século $\mathrm{XX}$, caracterizava-se pelo predomínio dos estabelecimentos ligados à produção de açúcar, álcool e aguardente. Ao lado do domínio desse centro, existiam já, desde o final do século passado, pequenos estabelecimentos industriais, que ocupavam mão-de-obra reduzida e se destinavam à produção de artigos para o consumo interno, como massas, vinagre, cerveja, sabão, móveis, colchões, louças de barro, artefatos de couro, carros de tração animal, arados, vassouras, telhas e tijolos.

É na década de 20 que se inicia outra fase da industrialização em Piracicaba, que vai se caracterizar pela expansão do setor metalúrgico e mecânico. Esse setor, voltado para a produção de equipamento completo para as usinas de açúcar e destilarias de álcool e aguardente, tem uma importância sempre crescente. Em 1920, instala-se em Piracicaba a Oficina Dedini que, no decorrer de sucessivos estágios de crescimento, veio a se tornar uma grande e diversificada empresa do setor metal-mecânico, com seu centro fundado na produção de equipamentos completos para usinas de açúcar e destilarias de álcool.

\subsection{CRIAÇÃO E ESTRUTURA DO ARRANJO PRODUTIVO DE ÁLCOOL DE PIRACICABA (APLA)}

Foi assinado o protocolo de intenção do APLA do Álcool de Piracicaba, em 15 de Fevereiro de 2006, pelo prefeito da cidade, Barjas Negri, pelo presidente da Aderp, José Carlos Borsari, e pelo representante da Secretaria Estadual de Ciência e Tecnologia, Castello Branco (ANHÃO, 2007).

Com a criação do arranjo produtivo local de Álcool em Piracicaba, envolvendo cerca 80 empresas, o poder público e entidades representativas aumentarão a procura por qualificação da base industrial de biocombustíveis e energias renováveis, consolidando um processo que poderá resultar no aprofundamento das relações das empresas locais com universidades e centros de pesquisa (SANTOS, 2007, p. 28).

Um dos objetivos do APLA é promover novos mercados para os produtos de Piracicaba, no crescente mercado mundial de biocombustíveis e energia renováveis, estimulando a competitividade de micro, pequenas e médias empresas da cadeia produtiva do setor, que muitas vezes desconhecem tecnologias e sistemas de gestão empresarial e não priorizam a inovação tecnológica.

Além da APLA, em 2004 foi implementado o pólo Nacional de Biocombustíveis nas dependências da Escola Superior de Agronomia Luiz de Queiroz (ESALQ), o que representa uma grande vantagem competitiva para Piracicaba e oportunidade única para fomentar o desenvolvimento da cadeia produtiva do município (SANTOS, 2007).

Um estudo sobre arranjos produtivos do Centro de Desenvolvimento e Planejamento Regional da Universidade Federal de Minas Gerais apontou Piracicaba como a maior aglomeração produtiva madura no setor metal-mecânico do País, observando-se a concentração geográfica de produtores, o grau de especialização e o acesso a crédito para novos projetos (SANTOS, 2007). Para esse autor, algumas empresas já estão se organizando em clusters com seus fornecedores, distribuidores e outros parceiros comerciais, operacionais e estratégicos.

RAI - Revista de Administração e Inovação, São Paulo, v. 5, n. 2, p. 92-111, 2008. 
ARTIGOS - Estratégias de inovação das empresas metalúrgicas no setor

Sucroalcooleiro de Piracicaba

Dessa forma estão disponíveis as condições adequadas para o início de um processo sustentável e duradouro de fomento à pesquisa, ao desenvolvimento e à inovação para as empresas de Piracicaba.

O APLA de Piracicaba desenvolve atividades que incluem planejamento, organização, qualificação e promoção das empresas integrantes da cadeia produtiva do álcool, estabelecidas na região de Piracicaba, estimulando também a padronização e certificação do álcool, para se tornar uma commodity, e o desenvolvimento de novas tecnologias e equipamentos (SANTOS, 2007, p. 51).

Constituem objetivos do arranjo produtivo local de Álcool de Piracicaba:

- fomentar a integração de seus participantes, de forma organizada e estruturada;

- criar oportunidades para a agregação de valor ao longo da cadeia industrial;

- atender de forma intensiva e abrangente às demandas de desenvolvimento sustentável da sociedade moderna, especialmente na questão de combustíveis renováveis;

- discutir os problemas da cadeia produtiva do setor sucroalcooleiro, possibilitando a diminuição dos custos de produção e aumentando a competitividade do álcool da região de Piracicaba, consolidando-se como referência em nível nacional e mundial;

- disseminação pelo mundo dos produtos, serviços, tecnologias e competências de seus integrantes (ANHÃO, 2007).

Dentro dessa proposta, foi criado um Plano de Promoção Comercial de Exportação no âmbito da Agência de Promoção de Exportações e Importações (APEX), órgão ligado ao Ministério da Indústria, Desenvolvimento e Comércio, visando à inserção das empresas do APLA junto à comunidade sucroalcooleira internacional.

$\mathrm{Na}$ região de Piracicaba, o APLA reúne destilarias, indústrias (grupo com 80 empresas do setor metal-mecânico e dez usinas da cadeia produtiva do setor sucroalcooleiro), centros de tecnologia e de pesquisa e escolas profissionalizantes. A realização é do Ministério do Desenvolvimento, Indústria e Comércio Exterior, Governo do Estado e Prefeitura de Piracicaba.

No diagnóstico realizado, com o apoio do Sebrae de Piracicaba, das indústrias que integram a cadeia produtiva, identificando gargalos nas áreas agrícola, industrial, de comércio e de logística, antes de definir um planejamento estratégico de ação, constatou-se a necessidade urgente de padronização do etanol para proteger as exportações brasileiras de eventuais barreiras técnicas impostas por países importadores de biocombustíveis. Outro gargalo na cadeia produtiva identificado pelo diagnóstico realizado pelo APLA foi a necessidade de qualificação de profissionais envolvidos em toda a cadeia produtiva. O APLA negociou com o Governo Estadual a instalação de uma Faculdade de Tecnologia com cursos voltados para a indústria do álcool e de biomassa, ao mesmo tempo que firmou convênio com o Ministério do Trabalho para o treinamento de cortadores de cana (IZIQUE, 2007, p. 28).

O álcool é estratégico e a meta é exportar, em 2007, 53 milhões de dólares da região de Piracicaba e, em 2008, outros 57 milhões de dólares, gerando mais de 5.500 novos empregos na região.

\section{METODOLOGIA E RESULTADOS DA PESQUISA}

RAI - Revista de Administração e Inovação, São Paulo, v. 5, n. 2, p. 92-111, 2008. 
Para a realização deste estudo, foi realizada pesquisa exploratória, baseada em fontes primárias, utilizando a abordagem direta aos representantes das micro, pequenas e médias metalúrgicas do Arranjo produtivo local do Álcool de Piracicaba, e pesquisa descritiva.

Os objetivos da pesquisa exploratória podem ser atingidos tanto com técnicas qualitativas como com as quantitativas, embora a pesquisa exploratória se baseie mais em técnicas qualitativas (COOPER; SCHINDLER, 2003, p. 131). Para Acevedo e Nohara (2006, p. 46) "o principal objetivo da pesquisa exploratória é proporcionar maior compreensão do fenômeno que está sendo investigado, permitindo assim que o pesquisador delineie de forma mais precisa o problema".

Foi feita também uma entrevista com os dirigentes da governança do APLA. A coleta de dados foi realizada através de um roteiro de entrevista com perguntas estruturadas e não-estruturadas. As perguntas não-estruturadas são abertas, em que o entrevistado responde com suas próprias palavras. São conhecidas também como perguntas de livre resposta. As estruturadas especificam o conjunto de respostas alternativas e o formato da resposta. Podem ser de múltipla escolha, dicotômica ou uma escala (MALHOTRA, 2006).

Nas questões estruturadas foi utilizada a escala de Likert, que consiste em afirmações que expressam atitudes favoráveis ou desfavoráveis, em relação ao objeto de interesse. Pede-se ao respondente que concorde ou discorde de cada afirmação (COOPER, 2003, p. 201).

O questionário de pesquisa foi aplicado por meio de entrevistas por telefone, que consiste, segundo Malhotra (2006), em telefonar para uma amostra de entrevistados e fazer uma série de perguntas. As perguntas não-estruturadas foram feitas por entrevista pessoal à entidade de criação e apoio do APLA, a Secretária de Indústria e Comércio.

Foi feito um survey em uma amostra das empresas, sem a preocupação de um rigor estatístico na escolha, uma vez que se tinha em conta que o acesso aleatório às empresas é prejudicado em razão da indisponibilidade de muitos empresários.

Após a aplicação do formulário de pesquisa aos empresários das metalúrgicas do APLA da região de Piracicaba, os dados foram tabulados e construídos tabelas e gráficos, a fim de que pudessem auxiliar na compreensão das proposições do estudo.

Entrevistou-se um total de 25 empresas metalúrgicas que atuam no setor sucroalcooleiro do APLA da região de Piracicaba, dos quais 4\% são micro-pequenas, $60 \%$ pequenas empresas, $28 \%$ médias empresas e $8 \%$ grandes empresas. O critério estabelecido seguiu a classificação do Serviço de Apoio às Micro e Pequenas Empresas (2005) sendo: empresas industriais - microempresas - até 19 empregados; empresas de pequeno porte - de 20 a 99 empregados; média empresa, de 100 a 499 empregados e grande empresa - 500 ou mais empregados.

Dos representantes das empresas metalúrgicas entrevistadas, $8 \%$ são diretores comerciais, $84 \%$ supervisores de venda e $8 \%$ auxiliares de venda.

O tempo da atividade das empresas pesquisadas, no setor metalúrgico, varia de quatro a 75 anos.

As principais atividades/produtos apontadas pelos entrevistados e desenvolvidas pelas empresas foram: fabricação e reforma de peças e equipamentos para o setor sucroalcooleiro e outras áreas.

Para simplificar as respostas dos entrevistados, foram unificadas as respostas dadas como Concordo Parcialmente e Concordo Totalmente em Concordo, e também as Discordo Parcialmente e Discordo Totalmente em Discordo, com o fim

RAI - Revista de Administração e Inovação, São Paulo, v. 5, n. 2, p. 92-111, 2008. 
de facilitar a análise dos resultados obtidos, levando-se em consideração as proposições colocadas inicialmente.

Na opinião de $92 \%$ das empresas pesquisadas houve concordância parcial com a afirmação de que as inovações na empresa se dão no processo produtivo e, para mesma questão, $8 \%$ concordaram totalmente. A Figura 1 mostra as respostas obtidas.

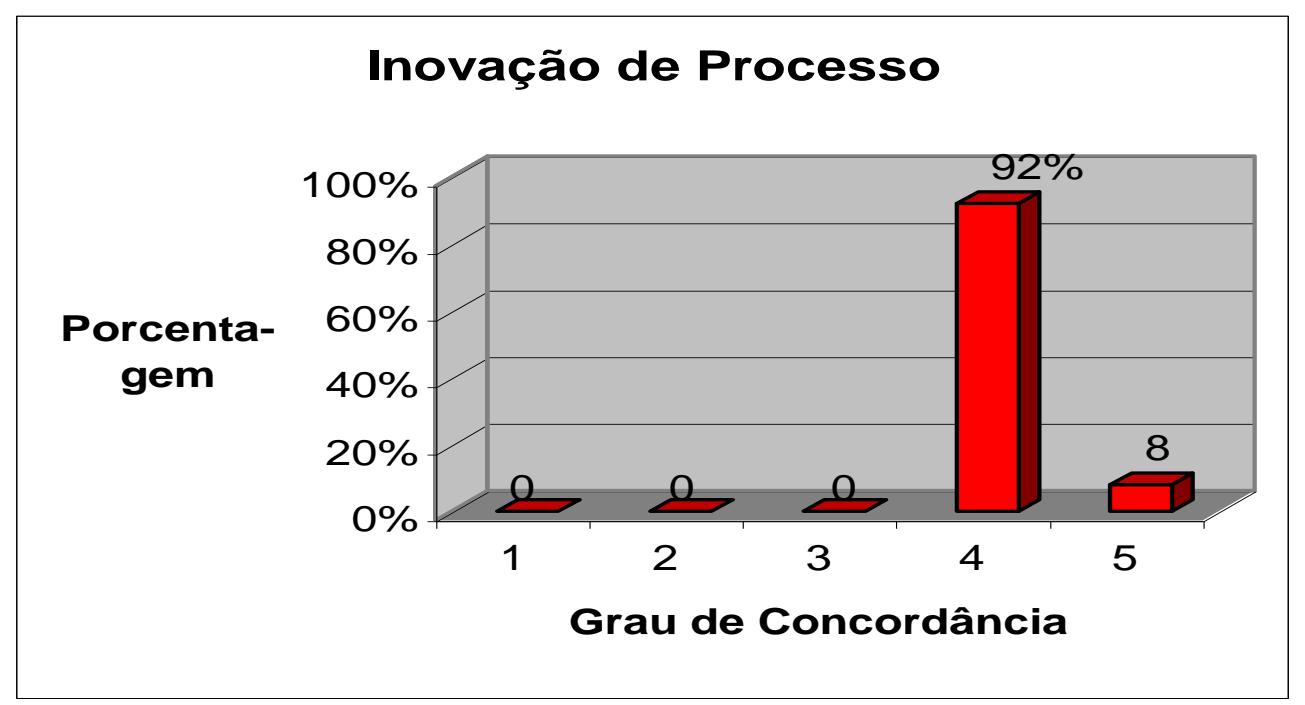

Figura 1. Inovações no Processo Produtivo Fonte: elaborada pelos autores

É interessante notar que nenhum pesquisado discordou que as inovações nas metalúrgicas do APLA de Piracicaba se dão no processo produtivo.

Com relação às inovações de produto, $12 \%$ concordaram totalmente e $84 \%$ concordaram parcialmente, afirmando que as inovações nas micro e pequenas empresas metalúrgicas ocorrem em produtos. Apenas $4 \%$ não discordaram nem concordaram; não houve discordância por parte das empresas. A Figura 2 ilustra as respostas obtidas.

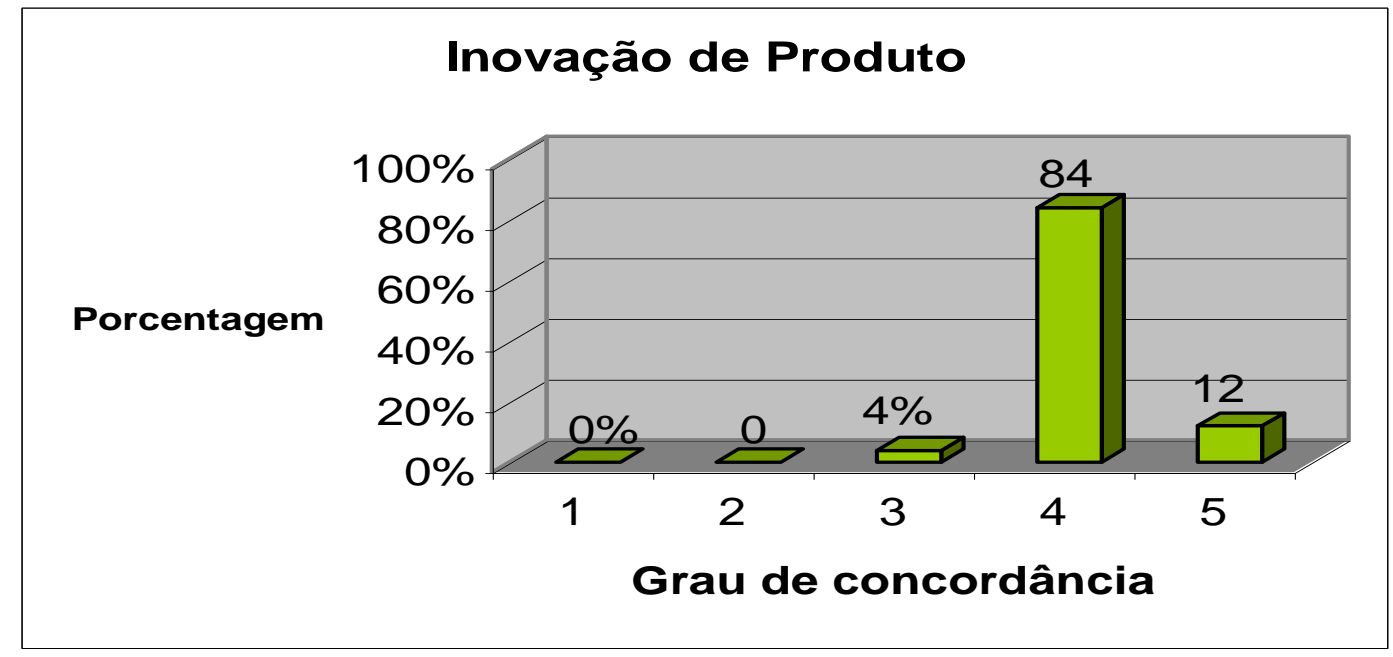

Figura 2. Inovações em Produtos

RAI - Revista de Administração e Inovação, São Paulo, v. 5, n. 2, p. 92-111, 2008. 
Fonte: elaborada pelos autores

Foi perguntado aos entrevistados se as inovações nas micro e pequenas empresas metalúrgicas ocorrem mais em processos produtivos do que em produtos, no intuito de verificar a veracidade da proposição. As respostas das questões mostram que $100 \%$ dos respondentes concordaram com a afirmação de que as inovações nas micro e pequenas empresas metalúrgicas se dão em processos de produção e $96 \%$ concordam com a afirmação de que as inovações nas micro e pequenas empresas metalúrgicas se dão em produtos. Portanto, há fortes indícios de que a proposição 1 não seja confirmada, as inovações nas micro e pequenas empresas metalúrgicas se dão mais em processos produtivos do que em produtos.

Foi perguntado aos entrevistados se as estratégias das empresas estão mais voltadas a atender às encomendas da empresa âncora do que a buscar novos mercados. A Figura 3 ilustra as respostas obtidas.

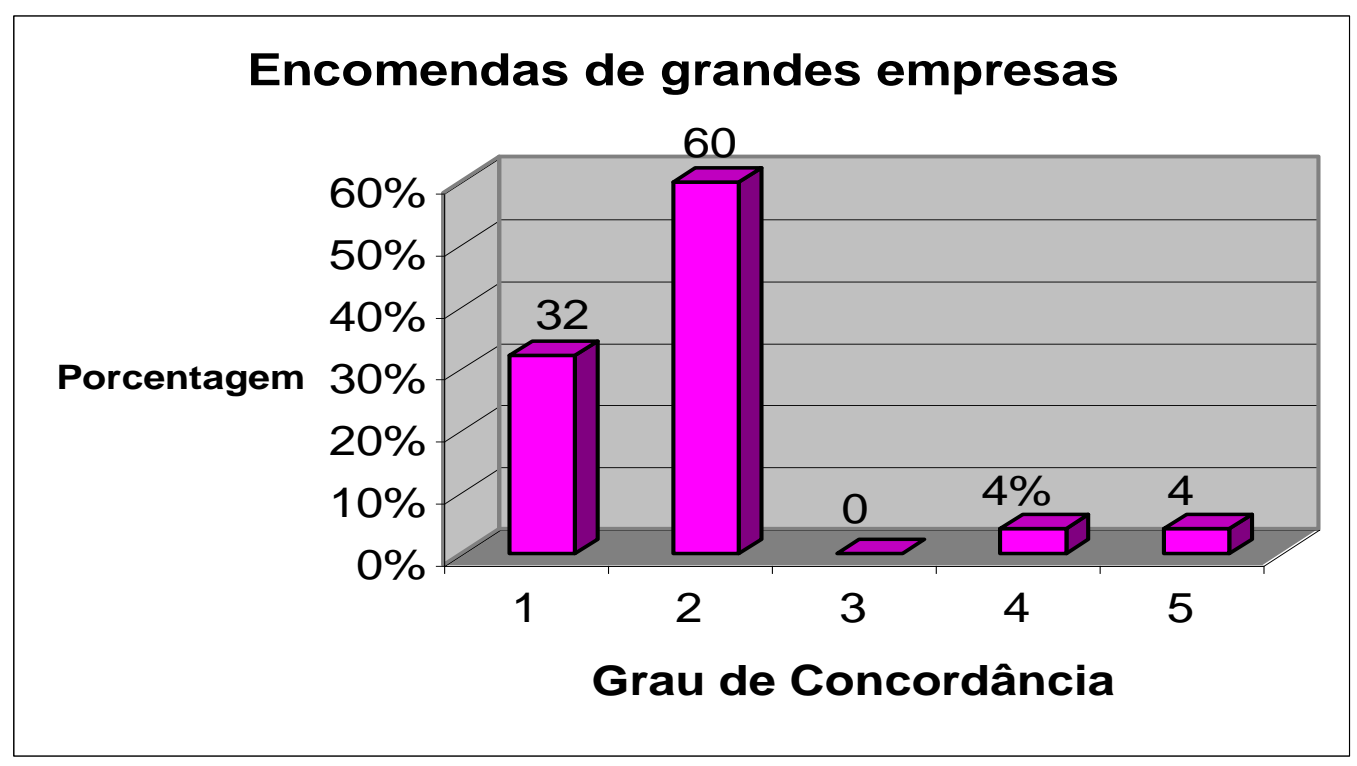

Figura 3. Encomendas de Grandes Empresas

Fonte: elaborada pelos autores

As respostas indicam que $92 \%$ dos respondentes discordaram e $8 \%$ concordaram com a afirmação de que as empresas atendem apenas às encomendas das grandes empresas metalúrgicas; $88 \%$ concordaram e $12 \%$ discordaram da ideia de que as empresas atendem às encomendas de todos os portes de empresas (pequenas, médias e grandes empresas). Ou seja, as micro e pequenas empresas metalúrgicas não atendem apenas às encomendas das grandes empresas metalúrgicas, vendendo seus produtos/serviços a outras empresas.

Em razão dos resultados encontrados, há fortes indícios que confirmam a proposição 2, as estratégias das empresas estão mais voltadas a atender as encomendas da empresa âncora do que a buscar novos mercados. 
Com respeito à afirmação de que as instituições acadêmicas (universidades, faculdades, institutos de pesquisa) estão criando ações para o aumento da inovação nas micro e pequenas empresas metalúrgicas do APLA da região de Piracicaba, $36 \%$ discordaram parcialmente e $64 \%$ não discordaram nem concordaram com essa afirmação, conforme Figura 4.

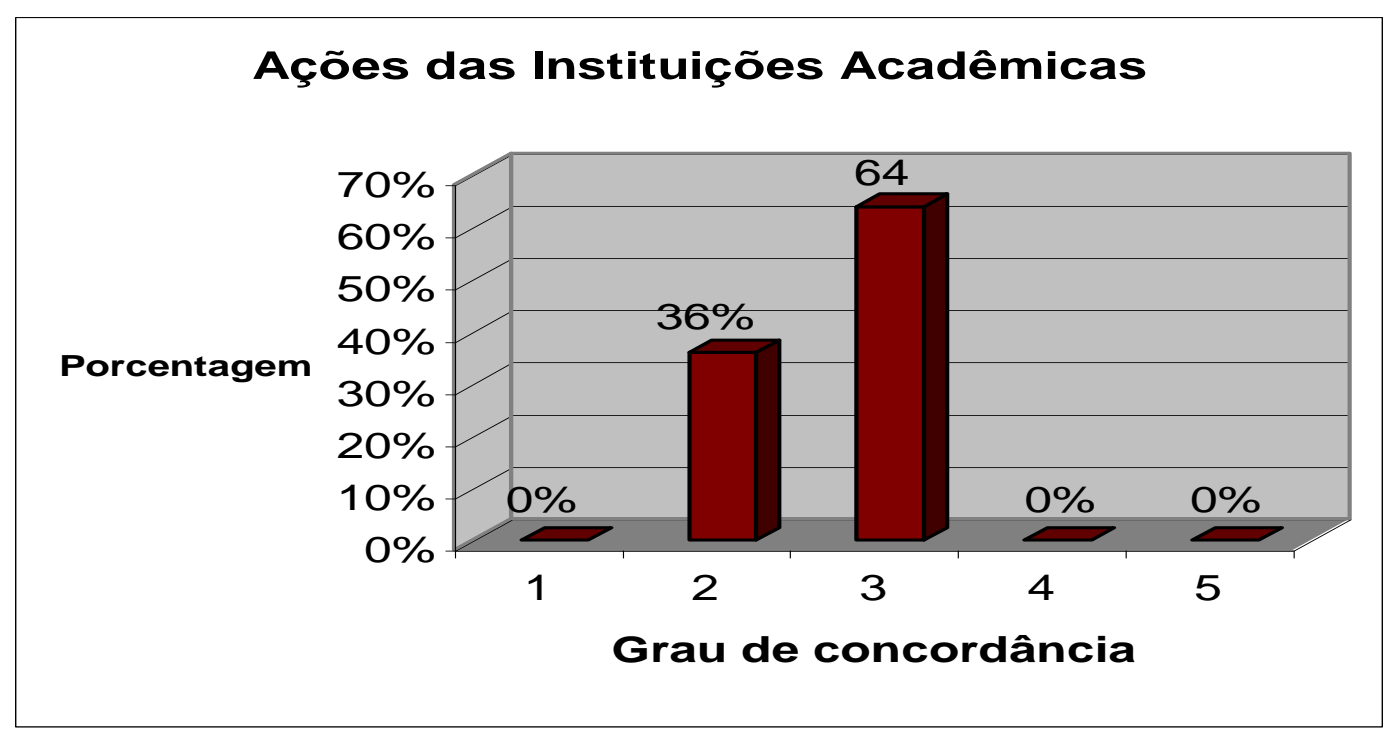

Figura 4. Ações das Instituições Acadêmicas Fonte: elaborado pelos autores

Com relação à proposição 3, as instituições acadêmicas estão criando ações para o fomento de inovações nas micro e pequenas metalúrgicas do APLA da região de Piracicaba, nenhum respondente concordou e $36 \%$ discordaram. Não há evidências de confirmar a proposição 3 , uma vez que mais que metade (64\%) das empresas pesquisadas não discordou nem concordou.

$\mathrm{Na}$ proposição 4, o esforço da governança em aproximar as empresas do segmento metalúrgico não tem surtido os efeitos desejados para aumento da inovação das micro e pequenas metalúrgicas, constatou-se que $96 \%$ concordaram e nenhuma empresa discordou da afirmação de que a governança tem tido êxito nas suas ações de aproximar as empresas do setor metalúrgico, com o fim de aumentar as inovações das micro e pequenas empresas. Assim sendo, há fortes indícios de que a proposição 4 não seja confirmada. A Figura 5 ilustra as respostas obtidas.

RAI - Revista de Administração e Inovação, São Paulo, v. 5, n. 2, p. 92-111, 2008. 
Zeferino Saraiva Henriques, Mário Sacomano Neto, Sílvia Helena Ramos Valladão de Camargo, Antônio Carlos Giuliani e Osvaldo Elias Farah

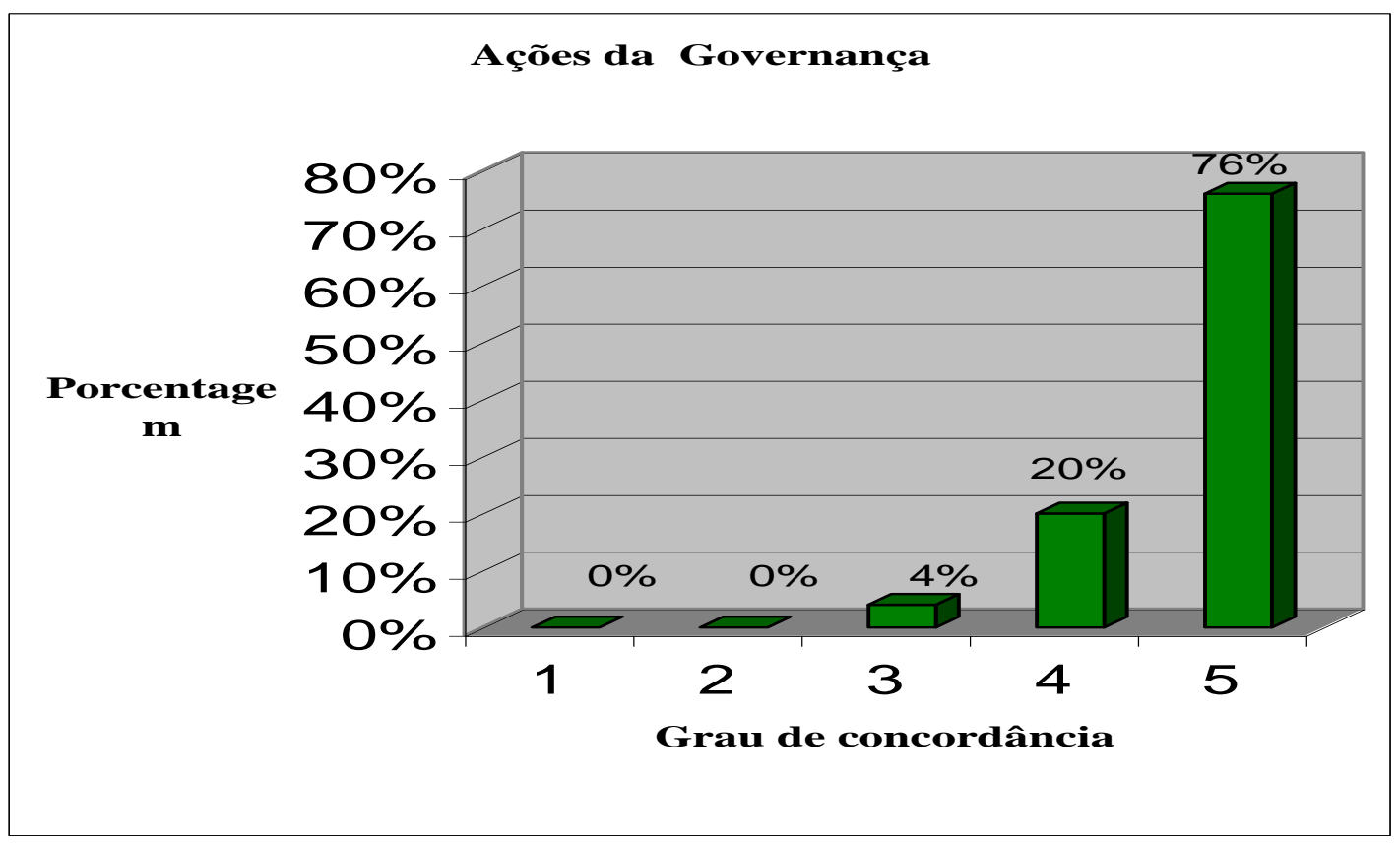

Figura 5. Ações da Governança.

Fonte: elaborada pelos autores

Com relação à troca de informações, os respondentes discordaram, $20 \%$ não discordaram nem concordaram e $76 \%$ concordaram com a existência de troca de informação entre as empresas sobre produtos ou processos de produção ou sobre mercados (vide Figura 6). Quanto à existência de cooperação entre empresas e seus fornecedores, $8 \%$ discordaram, $12 \%$ não discordaram nem concordaram e $80 \%$ concordaram (vide Figura 7). 
ARTIGOS - Estratégias de inovação das empresas metalúrgicas no setor

Sucroalcooleiro de Piracicaba

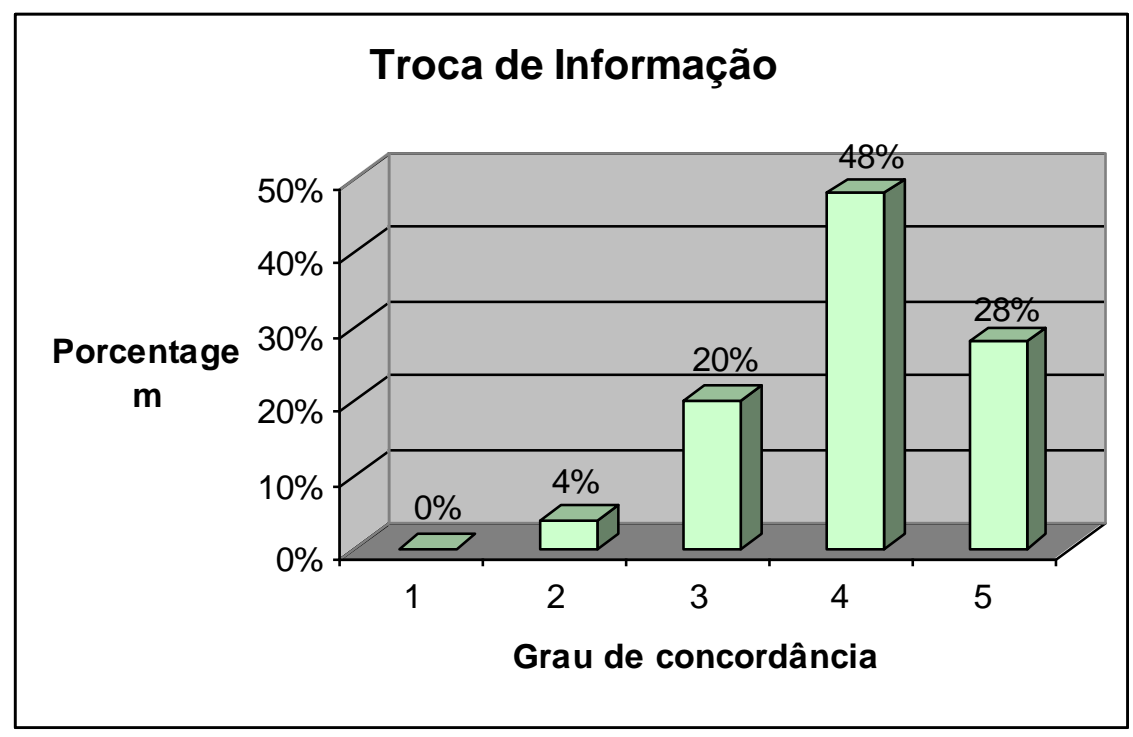

Figura 6: Troca de Informação

Fonte: elaborada pelos autores

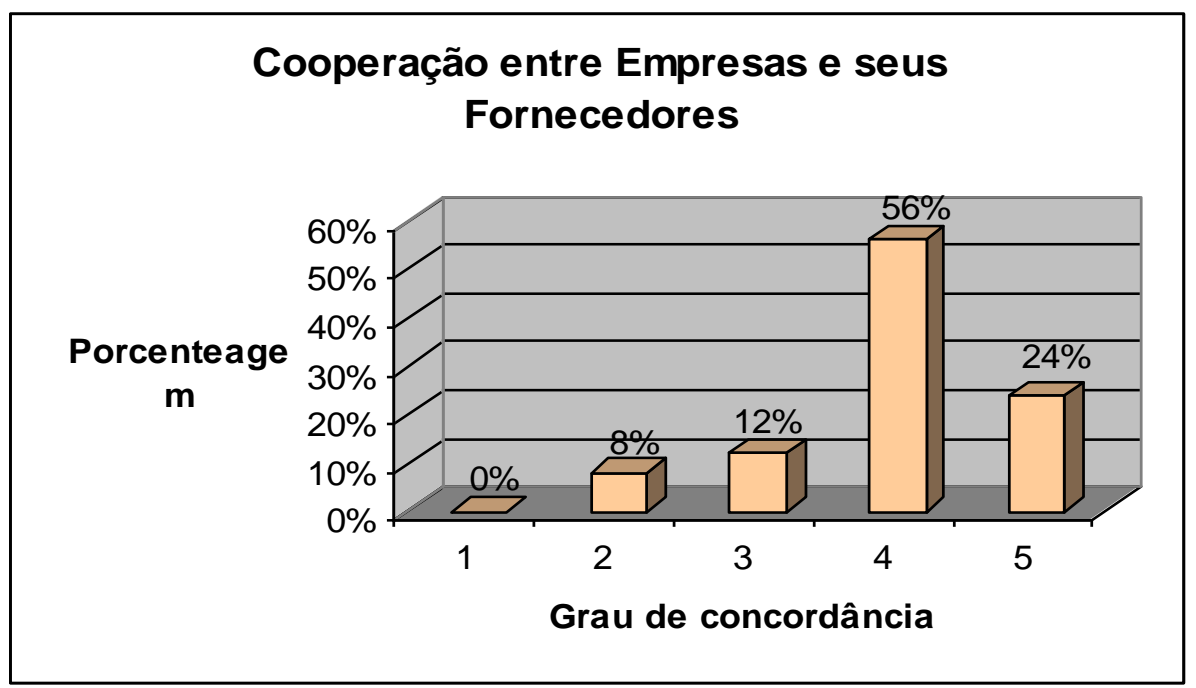

Figura 7. Cooperação entre Empresas e seus Fornecedores

Fonte: elaborada pelos autores

Os principais benefícios às empresas com a criação do Apla da região de Piracicaba, apontados pelo respondente de governança, foram: geração de oportunidades de negócios, aprimoramento da estrutura tarifária, qualificação profissional, estreitamento do relacionamento com os governos municipal, estadual e federal, criação de novos postos de trabalho, mais acesso às inovações tecnológicas e às linhas de crédito. A geração de negócios no setor sucroalcooleiro está alavancando as indústrias locais, o comércio, gerando emprego, criando áreas de atuação, agindo na divulgação do nome do município até para o exterior, beneficiando inclusive o turismo local.

Constatou-se que nem todas as instituições acadêmicas (universidades, instituições de pesquisa) estão próximas dos programas do Apla da região de Piracicaba, embora existam algumas que, de forma crescente, incluem em suas grades curriculares cursos para a qualificação de profissionais para o setor sucroalcooleiro. Escolas, como o Serviço Nacional da Indústria (Senai), oferecem cursos na área metal-mecânica. 


\section{CONSIDERAÇÕES FINAIS}

O objetivo central analisar as estratégias de inovação utilizadas pelas micro e pequenas empresas metalúrgicas que atuam no setor da agroindústria sucroalcooleira foi atingido. Pelos resultados que influíram nas proposições 1: as inovações nas micro e pequenas metalúrgicas se dão mais em processos produtivos do que em produtos, e na proposição 2: as estratégias das empresas estão mais voltadas a atender as encomendas da empresa âncora do que a buscar novos mercados, constatou-se que as inovações das micro e pequenas metalúrgicas se dão mais em produtos do que em processos produtivos, e as mesmas atendem a grande empresa líder e a outras empresas na montagem de usinas do país.

Verificou-se também que os empresários entrevistados apresentaram percepções que refletem aquilo que suas empresas esperam dos programas do APLA da região de Piracicaba. Embora sua criação seja recente, suas exigências não são pequenas.

$E$ foi com base nesse conceito que os pesquisadores formularam, na fase exploratória, a seguinte questão: qual a relação de cooperação entre empresas e fornecedores para incrementar o processo de inovação das pequenas e médias metalúrgicas?

Após a análise qualitativa deste estudo, percebeu-se que o APLA, em apenas um ano, já apresentou resultados importantes, como a assinatura dos dois projetos para ampliar o mercado do álcool e padronizar internacionalmente a produção do etanol. "Os convênios que assinamos são uma consolidação do trabalho do APLA e resultará em novas oportunidades de negócios para o etanol brasileiro no mercado mundial, evitando, por exemplo, barreiras técnicas e internacionais" (PIRACICABA, 2007, p. 1).

A pesquisa constatou que os empresários têm feito alianças entre si, com o objetivo de trocar informações sobre produção de novos produtos ou aprimorá-los, implementação de processos novos ou melhoria da produção e novos mercados. Como resultado das ações desenvolvidas pelo APLA, a interação entre os empresários tem se estreitado e gerado parcerias relacionadas a novos produtos e novas formas de produção.

As ações promovidas pelo arranjo produtivo local de álcool têm demonstrado, por um lado, a necessidade não só das ações conjuntas entre os participantes, como também das ações governamentais voltadas ao crescimento das micro, pequenas e médias empresas metalúrgicas do arranjo. Constituem ações que estão sendo implantadas na criação do APLA: ações de divulgação das empresas como feiras de negócios, apresentações, recepção de comitivas nacionais e internacionais, viagens ao exterior com grupos de 30-40 empresários das empresas participantes do APLA. Além dessas ações, está sendo implantado em Piracicaba o Parque Tecnológico de biocombustíves e bioenergia, o qual, além de congregar universidades, terá centros de pesquisa e desenvolvimento das empresas dos setores.

Apesar de existir um número acentuado de instituições acadêmicas na região de Piracicaba, a intervenção destas para o aumento das inovações nas micro e pequenas metalúrgicas é tímida ou não é bem percebida pelas empresas.

A aproximação entre empresas e universidades, com apoio do poder público, deve ser ampliada. Com a criação do APLA da região de Piracicaba, o poder público e as entidades representativas aumentarão a procura por qualificação da base industrial local, a fim de que haja o aperfeiçoamento e a criação de novos produtos para atender o crescente mercado mundial de biocombustíveis e energias renováveis, consolidando um

RAI - Revista de Administração e Inovação, São Paulo, v. 5, n. 2, p. 92-111, 2008. 
ARTIGOS - Estratégias de inovação das empresas metalúrgicas no setor

Sucroalcooleiro de Piracicaba

processo que poderá resultar no aprofundamento das relações das empresas locais com universidades e centros de pesquisa.

$\mathrm{O}$ esforço da governança em aproximar as empresas do segmento metalúrgico do setor sucroalcooleiro tem surtido efeitos desejados para o desenvolvimento de novos produtos ou produtos aprimorados e a adoção de processos novos de produção, nas micro e pequenas empresas metalúrgicas, resultado da confirmação da quarta proposição.

A pesquisa mostrou que a relação de cooperação entre empresas para o incremento do processo de inovação é verificada por meio da troca de informação sobre o desenvolvimento de produtos novos ou aprimorados e da adoção de novos processos de produção.

Pode-se concluir que a inserção das micro e pequenas empresas metalúrgicas no APLA da região de Piracicaba gera maiores possibilidades de desenvolvimento de novos produtos ou produtos aprimorados e a adoção de processos novos de produção, inovações necessárias para o desenvolvimento do segmento sucroalcooleiro brasileiro e sua consolidação mercantil em nível mundial.

Uma das limitações da pesquisa reside no fato de o APLA ter sido criado recentemente, não havendo tempo suficiente para os empresários assimilarem todas as ações propostas pelo plano diretor do mesmo. Por isso, em algumas questões, os respondentes colocaram-se numa posição neutra (não concordo nem discordo), como foi o caso da pergunta 5: as instituições acadêmicas: universidades, faculdades, institutos de pesquisa estão criando ações para o aumento da inovação das micro e pequenas metalúrgicas, em que $64 \%$ dos respondentes se colocaram na posição neutra.

Deve-se repetir o estudo no APLA de Piracicaba depois de passar algum tempo de sua existência, permitindo estudar a inserção das micro e pequenas empresas metalúrgicas no aglomerado, pois o presente estudo foi realizado pouco tempo após sua criação.

Em conjunto com APEX, o APLA da região de Piracicaba organiza viagens internacionais, que têm o objetivo de criar oportunidades para que as empresas do setor sucroalcooleiro realizem contatos e negócios no exterior.

Para reforçar competências nas áreas de pesquisa e de gestão de negócios, o Pólo Nacional de Biocombustíveis, em parceria com a ESALQ, a Fundação Getulio Vargas e a Empresa Brasileira de Pesquisa Agropecuária (Embrapa), criou o primeiro mestrado intrainstitucional em agroenergia, já aprovado pela Coordenação de Aperfeiçoamento de Pessoal de Nível Superior (CAPES) e que começará a funcionar em 2008 (IZIQUE, 2007).

Como é perceptível, o tema não se esgota! Novas pesquisas serão necessárias para entender e apoiar o desenvolvimento da produção do etanol na região e no país.

\section{REFERÊNCIAS}

ACEVEDO, C. R.; NOHARA, J. J. Monografia no curso de administração: guia completo de conteúdo e forma. 2. ed. São Paulo: Atlas, 2006.

\section{ALBAGLI, S.; BRITO, J. (Org). Glossário de arranjos e sistemas produtivos e} inovativos locais. Rio de Janeiro: RedeSist, 2003. 
Zeferino Saraiva Henriques, Mário Sacomano Neto, Sílvia Helena Ramos Valladão de Camargo, Antônio Carlos Giuliani e Osvaldo Elias Farah

AMARAL FILHO, J. et al. Identificação de arranjos produtivos locais no Ceará. In: LASTRES, H. M. M.; CASSIOLATO, J. E.; MACIEL, M. L. (Org.). Pequena empresa: cooperação e desenvolvimento local. Rio de Janeiro: Relume Dumará, 2003. cap. 5.

ANHÃO, L. Semic organiza reunião para apresentação do APLA. Disponível em: <http://www.piracicaba.sp.gov.br/goto/store/textos.aspx?SID=93aa87cc39ad7054f4281 8924b8e11b0\&id=443>. Acesso em: 11 abr. 2007.

BEJERANO, R. F. Innovación organizacional. In: (Coord.). Gestión de la innovación: una visión actualizada para el contexto iberoamericano. Havana: Academia, 2006.

CASSIOLATO, J. E.; LASTRES, H. M. M. Globalização e inovação localizada: experiência de sistemas do Mercosul. Brasília: IBICT/MCT, 1999.

CIPOLLA, J. H.; CAVALCANTI, M.; SOUZA, R. C. Compartilhamento e competição: inovação e tecnologia na área cerâmica. In: COSTA, B. K.; ALMEIDA, M. R. (Org.). Modelos e inovações em estratégia. São Bernardo do Campo: Unimep, 2007. p. 245 260.

COOPER, D. R.; SCHINDLER, P. S. Métodos de pesquisa em administração. 7. ed. Porto Alegre: Bookman, 2003.

DORNELAS, J. C. A. Empreendedorismo corporativo: como ser empreendedor, inovar e se diferenciar na sua empresa. Rio de Janeiro: Campus, 2003.

HAMEL, G. O laboratório de inovação em gestão. HSM Management, Barueri, v. 12, n. 58, p. 120-126, out. 2006.

HITT, M. A.; IRELAND, R. D.; HOSKISSON, R. E. Administração estratégica: competitividade e globalização. São Paulo: Pioneira Thomson Learning, 2002.

IZIQUE, C. Ponto de ebulição: ação articulada entre governo, setores de produção e de pesquisa projeta Piracicaba no mercado mundial do etanol. Disponível em: <http://www.revistapesquisa.fapesp.br/?art=3343\&bd=1\&pg=1\&lg>. Acesso em: out. 2007.

LASTRES, H. M. M.; CASSIOLATO, J. E.; MACIEL, M. L. (Org.). Pequena empresa: cooperação e desenvolvimento local. Rio de Janeiro: Relume Dumará, 2003.

MALHOTRA, N. K. Pesquisa de marketing: uma orientação aplicada. 4. ed. Porto Alegre: Bookman, 2006.

ORGANIZAÇÃO PARA COOPERAÇÃO ECONÔMICA E DESENVOLVIMENTO. Manual de Oslo: proposta de diretrizes para coleta e interpretação de dados sobre inovação tecnológica. Tradução Financiadora de Estudos e Projetos. Brasília: Finep, 2004.

PIRACICABA. Prefeitura Municipal. Convênios projetarão Piracicaba para o mundo. Disponível em:

<http://www.piracicaba.sp.gov.br/goto/store/textos.aspx?SID=8051bf7506cb26ecf9221 0467ab755ea\&id=3345>. Acesso em: 10 nov. 2007.

RAI - Revista de Administração e Inovação, São Paulo, v. 5, n. 2, p. 92-111, 2008. 
PORTER, M. E. Competição, on competition: estratégias competitivas essenciais. Rio de Janeiro: Campus, 1999.

PORTER, M. E. Vantagem competitiva: criando e sustentando um desempenho superior. Rio de Janeiro: Campus, 1989.

SÁENZ, T. W.; SOUSA PAULA, M. C. de. Innovación tecnológica y sustentabilidad. In: BEJERANO, R. F. (Coord.). Gestión de la innovación: una visión actualizada para el contexto iberoamericano. Havana: Editorial Academia, 2006.

SANTOS, J. R. (Org.). Piracicaba 2010: realizando futuro. Disponível em: <http://www.piracicaba2010.com.br>. Acesso em: 24 maio 2007.

SERVIÇO BRASILEIRO DE APOIO ÀS MICRO E PEQUENAS EMPRESAS.

Pesquisa geral no site. Disponível em: 〈http://www.sebrae.com.br/paginaInicial>. Acesso em: 20 jul. 2005.

TAUHATA, T. L.; MACEDO-SOARES, T. D. L. V. A. Redes e alianças estratégicas no Brasil: caso CVRD. RAE-eletrônica, v. 3, n. 1, art. 4, jan./jun. 2004.

\title{
INNOVATION STRATEGIES OF METALLURGIC COMPANIES SUPPLIERS OF SUGAR-ALCOHOL SECTOR
}

\begin{abstract}
The innovation is the considered the motor which moves the economic development and to study the processes through which innovations are introduced and spread out is one of the biggest challenges to the regional and global economy. This article analyzes the innovation strategies of metallurgic companies supplying of the sugar-alcohol sector and some others pertaining to the alcohol local productive arrangement of Piracicaba (APLA). The research is of exploratory and descriptive type, and was carried through with 25 companies of the sector metal-mechanic, most part of them micron, small and medium extent companies. The results of the research showed that the innovations in micron and small companies occur more in products, than in productive processes. Amongst the difficulties found by the companies it is presented tax burden and the raised tax of interests, as well as, restricted access to technologies, credit and markets. Results of the research also show that the insertion of the companies in the APLA has generated bigger possibilities of innovation in products and processes to support the growth and advance of Brazilian ethanol in the world-wide markets.
\end{abstract}

Keywords: Innovation. Local productive arrangements. Small companies.

Data do recebimento do artigo: 17/05/2008

Data do aceite de publicação: 07/08/2008

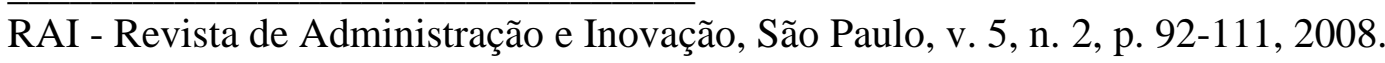

